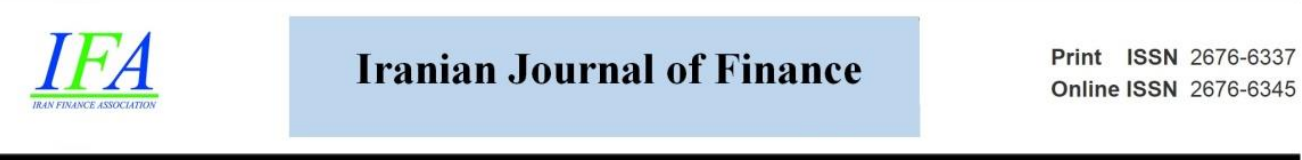

\section{Analysis of Sovereign External Debt Variations by Cross Wavelet Transform}

\section{Ali Namaki}

Assistant Prof., Department of Finance and Insurance, Faculty of Management, University of Tehran, Iran. (Email: alinamaki@ut.ac.ir)

Iran Finance Association, Tehran, Iran.

\section{Mohsen Nazari}

Associate Prof., Department of Business Management, Faculty of Management, University of Tehran, Tehran, Iran. (Email: mohsen.nazari@ut.ac.ir)

\section{Hossein Gaeeini*}

*Corresponding Author, MSc. of MBA, Faculty of Management, University of Tehran, Tehran, Iran. (Email: hgaeeini@gmail.com)

Document Type: Original Article

Received: 2020/08/25

Accepted: 2020/11/30

2020, Vol. 4, No. 4. 126-139

Published: 2020/12/01

\section{Abstract}

Since the 1970's developing and developed countries have experienced unprecedented public debt levels. This surge in public debt has emphasized the importance of public debt management. Since risks such as reducing economic growth, increasing inflation, and depreciation of the national currency accompany unplanned public debt accumulation, governments should be alert not to endanger economic growth with illconsidered borrowing. In this paper, we aim to analyze Iran's external debt variations concerning major macroeconomic variables such as GDP growth as a proxy of economic growth, inflation, and sovereign oil generated incomes. The method that is applied in this research is cross wavelet transform which is a powerful mathematical approach for analyzing the financial data.

Our results show there are different patterns in small and large scales between variables and external debt as a dependent variable has different relations with endogenous and exogenous factors. In the short run, low oil prices as an exogenous variable, during the 1980s have shaped governments' debt accumulation behavior but on larger scales, indigenous variables such as governments' budget deficits have been much more dominant in shaping governments borrowing patterns. In a chronological view, US cruel sanctions and the Iran-Iraq war were major events affecting sovereign borrowing behavior.

Keywords: Public Finance, Sovereign Debt, Cross Wavelet Transform, International Capital Flows, Developing Economy.

DOI: 10.30699/iif.2020.121947 Copyright: author(s)
Publisher: Iran Finance Association Type of License: Creative Commons License (CC-BY 4.0) 


\section{Introduction}

Public finance is related to the role of government in the economy (Gruber, 2005). This field of study is mainly concerned with the adjustment of government revenues and expenditures in a manner to achieve desired outcomes and this is an important issue for both policymakers and citizens (Jain, 1974).

What are the sources of financing? What is the optimal source of financing? - Tax, domestic debt, external debt, or a combination of different sources - are just some of the questions regarding financing sovereign expenditures that are answered in different researches.

Tax is considered the most important source of revenue for governments but there are some challenges following the increase in taxes such as reductions in the output of the economy (Casalin, Dia and Hallett, 2020).

Debt provides governments with tax smoothing benefits as noted in (Barro, 1979, 1991, 2008) (Bohn, 1990) and allows them to raise revenues quickly in case of catastrophic events (Casalin, Dia and Hallett, 2020).

Another factor that should be considered is the income from natural resources in different countries such as Iran (Chiodo and Owyang, 2002; Emami and Adibpour, 2012; Mohaddes and Pesaran, 2012) which makes these countries much prone to income shocks.

In a historical view, sovereign debts' beginnings traced back to monarchies to finance their war efforts (Frederiksen, 1966). But over time, with the progress of societies and the emergence of new needs such as maintaining social security, sovereign borrowing has found new purposes (Eichengreen, 1998; Stasvage, 2011). Consolidation of smaller city-states led to the emergence of larger governments with more revenues. This increase in revenues along with restrictions on rulers' power led to more government accountability (Eichengreen, 2019).

Generally, sovereign debt can be categorized as domestic and external. External debts are issued under legal jurisdictions of foreign governments, mostly denominated in foreign currencies and held by foreign citizens. On the contrary, domestic debt legal disputes are ruled by home sovereign legal jurisdictions, mostly denominated in home sovereign currency and mainly held by residents (Reinhart, Rogoff, 2011). Sovereign debts are considered as riskfree assets because it is supposed that governments can make their repayments by increasing taxes or inflating the economy (Oosterlinck, 2011). 
There are substantial differences between private and public debts. In case of default and other relevant disputes with the borrower, private debt creditors can protect their interests by taking legal action against the borrower but in the case of public debt, there aren't many options for creditors to protect their interests.

Public debts in developed and developing countries have soared to unprecedented levels since the World Wars. In 2010, the average public debt to GDP ratio of developed economies surpassed World War peaks (Reinhart and Rogoff, 2011).

This accumulation of debt has grown concerns about sovereigns' capability to repay debts. Imprudent debt accumulation comes with several risks ranging from downgrading sovereign debt rating and decreasing the economic growth and leads to financial crises. We can mention the Russian debt crisis in 1998 and the Argentina debt crisis in 2001 as examples (Paddock, 2002).

Government failures in debt repayments result in other drastic consequences such as cut off from international capital markets (Obstfeld and Rogoff, 1996), extreme inflations in developing countries (Reinhart, Rogoff2010), shrinking the economic growth in both developing and developed countries which are more severe in developing countries (Reinhart and Rogoff, 2010; Kumar and Woo, 2010), the interest rate jumps ahead of sovereign debt crises (Chang and Velasco, 2001).

External debt as a considerable portion of public debt composition is studied extensively. Trade, inflation, and economic growth are exogenous or endogenous external debt determinants as noted in (Bittencourt, 2015; Awan, Anjum, and Rahim, 2014; Hilscher and Nosbusch, 2010). Having said that, the accurate analysis of external debt and its relation with macro-economic variables is a controversial issue.

Few works have considered the theoretical complexity of the economic variables and their structures (Arthur, 1999; Namaki et al, 2011; Hosseiny et al, 2016; Shirazi et al, 2017; Raei, Namaki and Vahabi, 2019; Namaki et al, 2019; Pearce, 1994; Helbing and Kirman, 2013; Hosseiny et al, 2019; Bahrami et al, 2020; Varela et al, 2015). The gap between the applying complexity notions on the analysis of external debt leads us to use new methods.

As the economy is the result of interaction between a huge number of agents that simultaneously have interactions with each other and their environment (Schweitzer, Fagiolo, and Sornette, 2009; Lai et al, 2020) and 
these agents pursue many objectives on different scales and frequencies (Marco Gallegati et al, 2011), it is important to gain in-depth insight on these frequency variations.

For years, it was common to analyze these variations in frequency employing Fourier analysis (Conraria, Azevedo and Soares, 2008). It is not possible to discover transitions and structural changes, and methods such as Fourier transform are suitable for time series with stable statistical properties (Conraria and Soares, 2013). Wavelet transform is one of the alternatives to Fourier transform that has been used extensively in engineering (Grinsted, Moore and Jevrejeva, 2004).

Wavelet analysis, as a suitable substitute for Fourier analysis, can provide more insights into complexity economic by considering relationships between variables in different frequencies and time scales (Conraria, Azevedo and Soares, 2008). Traditionally, Fourier analysis is employed in economics and finance to discover dynamic and time-varying relationships between variables (Gallegati and Semmler, 2014). Limitations of Fourier analysis such as failure in discovering structural changes and limitations on processing non-stationary time series which are quite common in finance and economics resulted in the increasing utilization of wavelet analysis in economics and finance as a substitute for Fourier analysis (Gallegati and Semmler, 2014).

Very few research studies have analyzed the relationship between macroeconomic variables in different frequencies especially considering external sovereign debt (Swastika, Dewandaru and Masih, 2013; Aloui et al, 2018); hence leading us to questions of this paper. In this paper, by applying the cross wavelet approach on macroeconomic variables from 1352 (1973) to 1398 (2019), we aim to analyze relations between sovereign external debt vs economic growth, oil revenues, and inflation in Iran and applying cross wavelet transform in different frequencies to gain better insights into relations between these variables in different timescales. By utilizing wavelet transform, we can overcome the limitations of Fourier transform and discover valuable knowledge about the relationship between these variables.

Our paper is organized as follows. In section 2 the methods are presented and, in section 3 we show the findings. Then, in section 4 we conclude.

\section{Methods}

Fourier analysis is used to analyze frequency properties of time series but as it was mentioned in the previous section and papers such as (Aguiar and 
Conraria, 2008; Gabor, 1946; Raihan, Wen and Zeng, 2005), Fourier transform faces several drawbacks when it comes to analyzing time series with unstable statistical properties which is the case for most of the economic series (Aguiar and Conraria, 2008). Many scholars have used wavelet transform for economic applications.

In (Cascio, 2015), USA debt sustainability was analyzed in different timescales utilizing wavelet transform to depict a longitudinal picture of different macroeconomic variables and behavior of different administrations in the USA towards sovereign debts.

Continuous wavelet transform is described as follows:

$$
W_{x}(s, \tau)=\int_{-\infty}^{\infty} x(t) \frac{1}{\sqrt{s}} \psi^{*}\left(\frac{t-\tau}{s}\right) d t
$$

Discrete wavelet transform is defined as follows:

$$
W_{n}(s)=\sum_{n^{\prime}=0}^{N-1} x_{n}, \psi *\left[\frac{\left(n^{\prime}-n\right) \delta t}{s}\right]
$$

Where $*$ denotes complex conjugation. The parameter $\mathrm{s}$ and $\tau$ are scaling factor and location parameter. Scaling a wavelet means stretching for $(|s|>1)$ and compressing for $(|s|<1)$. The complexity of the wavelet function $\psi(t)$ leads to the complexity of the wavelet transforms $\mathrm{W}_{\mathrm{x}}$. The transform can be bisected into the real part $\left(\mathrm{R}\left\{\mathrm{W}_{\mathrm{x}}\right\}\right)$ and imaginary part $\left(\mathrm{I}\left\{\mathrm{W}_{\mathrm{x}}\right\}\right)$, or amplitude, $\left|\mathrm{W}_{\mathrm{x}}\right|$. The phase of time-series $\mathrm{x}(\mathrm{t})$ can get values from $-\pi$ to $\pi$. To divide the phase and magnitude of a time-series, the complex wavelets can be used.

To find local covariance between variables, the cross wavelet power spectrum $\left|\mathrm{W}_{\mathrm{xy}}(\mathrm{u}, \mathrm{s})\right|$ can be used, where: (Torrence and Compo, 1998)

$$
W_{n}^{X Y}(s)=W_{n}^{X}(s) W_{n}^{Y^{*}}(s)
$$

The intensity of covariance is found by:

$$
\rho_{x y}=\frac{S\left(W_{x y}\right)}{\left(S\left(\left|W_{x}\right|^{2}\right) S\left(\left|W_{y}\right|^{2}\right)\right)^{0.5}}
$$


Lead lag relation between variables is given by:

$$
\phi_{x y}=\operatorname{Arctan}\left(\frac{\operatorname{Im}\left(S\left(W_{x y}\right)\right.}{\operatorname{Re}\left(S\left(W_{x y}\right)\right.}\right)
$$

Different values $\phi_{x y}$ indicate different lead-lag relation between variables. When $\phi_{x y}$ in a specified time-frequency is zero, time series move together. If $\phi_{x y} \in\left(0, \frac{\pi}{2}\right)$ or $\phi_{x y} \in\left(-\frac{\pi}{2}, 0\right)$, series are positively correlated, and $\mathrm{x}$ leads $\mathrm{y}$ and y leads $x$, respectively. In the same manner, if $\phi_{x y} \in\left(\frac{\pi}{2}, \pi\right)$ or $\phi_{x y} \in\left(-\pi,-\frac{\pi}{2}\right)$ series are negatively correlated, and $\mathrm{x}$ leads $\mathrm{y}$ in the latter and $\mathrm{y}$ leads $\mathrm{x}$, respectively (Cascio, 2015).

There are requirements for a wavelet function to be acceptable, that it should fulfill the following equation: (Daubechies, 1992)

$$
0<C_{\psi}:=\int_{-\infty}^{\infty} \frac{|\psi(\omega)|}{|\omega|} d \omega<\infty
$$

Our data in this paper consists of the period, 1352 (1973) - 1398 (2019), in which the largest consistent data of required macroeconomic variables were available. Macroeconomic variables include GDP growth as a proxy of economic growth, annual inflation rate, external debt, and oil revenues which were extracted from CBI, the central bank of Iran, and the World Bank.

After normalizing time series, cross wavelet transform is implemented with external debt as y - dependent variable - and each time one of the variables annual inflation, GDP growth, and oil revenues are taken as $\mathrm{x}-$ independent variable -. To illustrate the results of the cross wavelet transform, we use a heat map chart so we can exhibit components of the cross wavelet transform output matrix.

Many functions fulfill equation (6) but the most used and studied functions are Morlet, Haar, Daubechies, Complex Gaussian, and Mexican Hat. As one of our requirements in the paper is to analyze lead-lag relations between variables, a complex wavelet is favorable (Cascio, 2015) which we used a Complex Gaussian mother wavelet. The general form of Complex Gaussian wavelet is as follows in equation 7: 


$$
f(x)=C_{p} e^{-i x} e^{-x^{2}}
$$

Using higher orders of Complex Gaussian wavelet can improve the resolution of results but it has a high computational cost (Wang et al, 2011; Yang et al, 2011). In this paper, we used a fourth-order complex Gaussian mother wavelet because orders higher than fourth made no noticeable improvement. Figure 1 depicts a fourth-order complex Gaussian wavelet by real and imaginary parts.
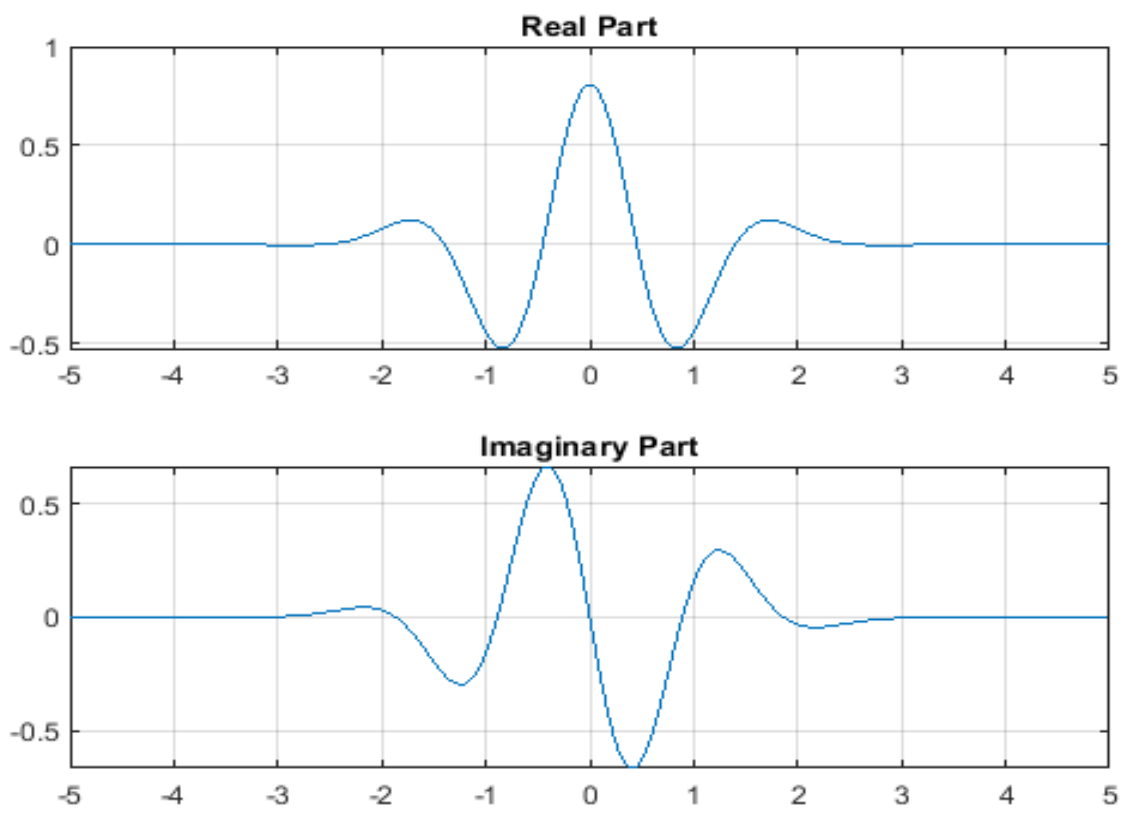

Figure 1 - Two parts of Complex Gaussian wavelet

\section{Results}

In Figure 2, a cross wavelet transforms output chart for GDP growth and external debt from 1352 (1973) to 1398 (2019) is exhibited. Because of the small size of our dataset, results in larger scales are less reliable. So we focus on smaller scales in all of the analyses. From 1352 (1973) to 1360 (1981), we can see a negative correlation between GDP growth and external debt that means an increase in GDP growth results in decreasing the external debt. Over time, from 1360(1981) to $1364(1985)$ this correlation changes to positive relation with GDP growth leading to external debt. So we can infer a change in 
sovereign borrowing behavior.

After 1367 (1988), sovereign borrowing behavior reaches a relatively stable situation, and an increase (decrease) in GDP growth results in a buildup (decrease) of external debt until 1394 (2015). After 1394 (2015), one can observe external debt adversely affects GDP growth.

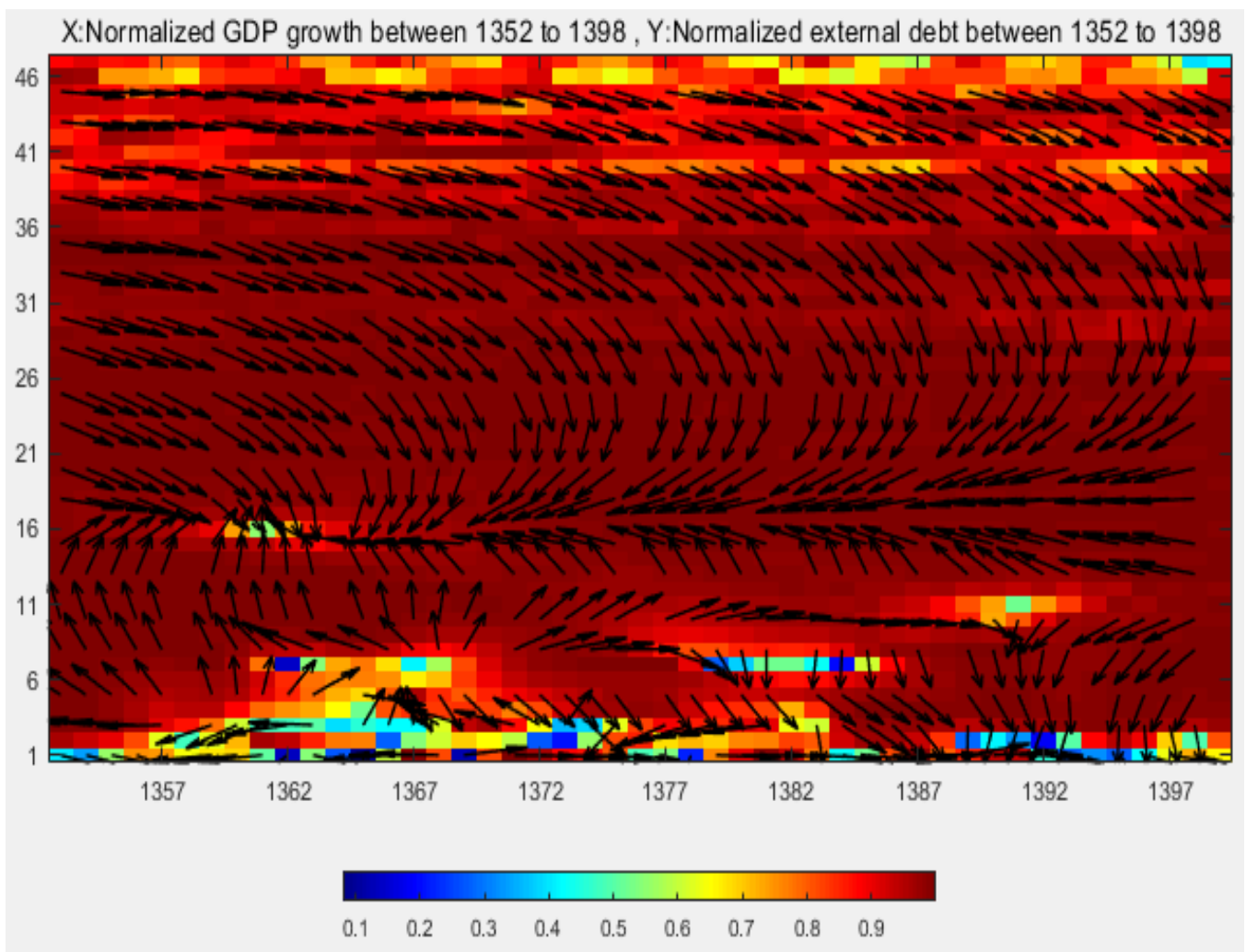

Figure 2 Cross wavelet transform output chart for GDP growth and external debt from 1352 (1973) to 1398 (2019)

In Figure 3, a cross wavelet transforms output chart for external debt and annual inflation from 1352 (1973) to 1398 (2019) is exhibited. From 1352 (1973) to 1372 (1993) - a positive correlation is observed and annual inflation leads to increasing the external debt. From 1372 (1993) to 1374 (1995) again one can observe a positive correlation but this time external debt affects the inflation rate. From 1374 (1995) to 1385 (2006) gradually two-time series begin to move together. From 1385 (2006) to 1398 (2019) annual inflation rate causes external debt changes. From 1352 (1973) to 1398 (2019) except period 1372 (1993) to 1374 (1995), there is a positive relation between external debt 


\section{Iranian Journal of Finance, 2020, Vol. 4, No. 4 (Namaki, A.)}

and annual inflation which leads the external debt. In an accurate analysis, one of the main causes of such a pattern is long-lasting periods of high inflation which affects directly external debt. On the other side, from 1372 (1993) to 1374 (1995) unlike other periods, external debt leads the inflation. So one can observe a dramatic change in sovereign borrowing. The missing link to clarify causes of this change is disproportionate to sovereign borrowing which results in a sovereign debt default. So, just like other episodes of sovereign debt default or restructuring, governments are compelled to devalue national currency.

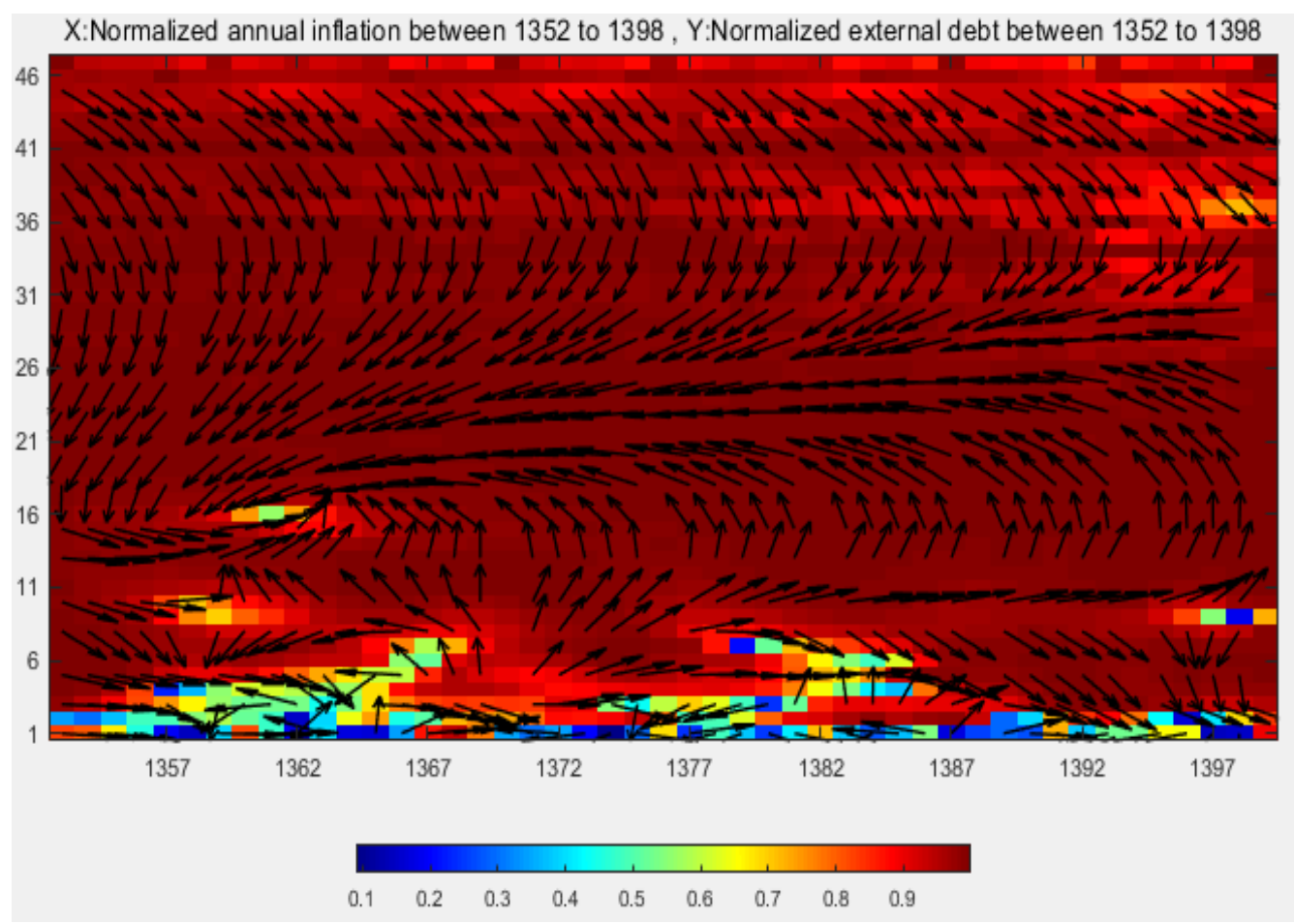

Figure 3 Cross wavelet transform output chart for external debt and annual inflation from 1352 (1973) to 1398 (2019)

In Figure 4, we can see that from 1352 (1972) until 1362 (1983), variables move together concurrently. Until 1375 (1996), the relation between oil revenue and external debt changes, and during this time external debt affects oil revenues. From 1375 (1996) to 1383 (2004), we cannot see a uniform pattern but gradually, variables' correlation becomes positive and oil revenues lead the external debt. This behavior continues until 1398 (2019). An increase in oil prices and also in Iran oil-producing capacity can be considered as the main causes. 


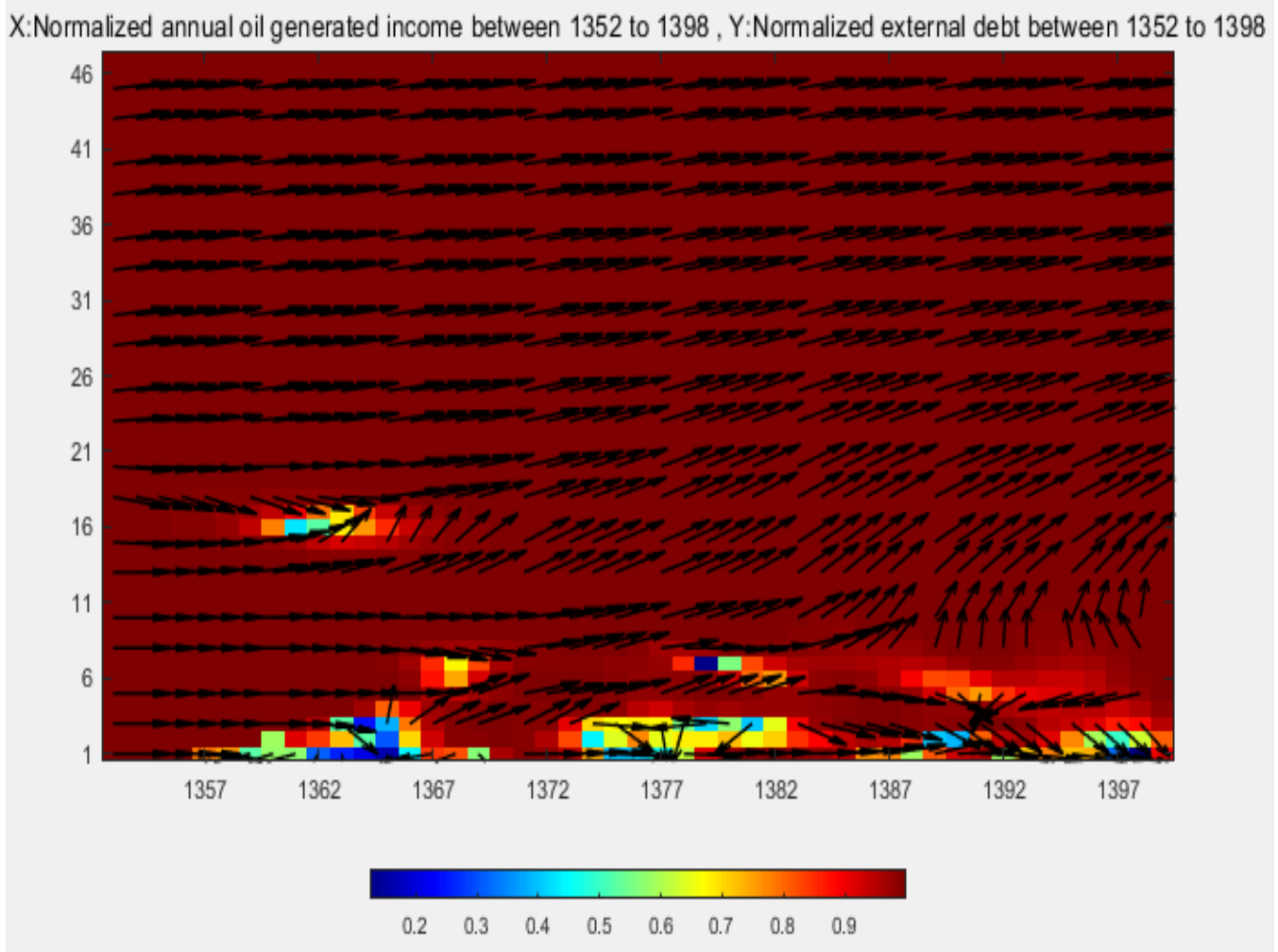

Figure 4 Cross wavelet transform output chart for external debt and oil revenues from 1352 (1973) to 1398 (2019)

\section{Conclusions}

In this paper, the behavior of Iran's external debt variations concerning major macroeconomic variables has been analyzed by cross wavelet transform. The results show different behavior between external debt and macroeconomic variables. Although different dynamics are governing endogenously variables such as annual inflation rate and GDP growth and exogenous macroeconomic variables such as oil price, through careful analysis of cross wavelet transform heat maps, which are the representation of cross wavelet transform vectors, we can reach several results. There are different behaviors in the short-run and long-run. It must be considered that the aforementioned endogenous variables are affected by environmental factors. Iran-Iraq war, the dramatic decline of oil price in the 1980s, and USA cruel sanctions are among the key points in understanding Iran's external debt variations.

In the 1360s (1980s), with the eruption of the Iran-Iraq war, there was a 
surge in external debt stockpiles that coincided with low oil prices which resulted in decreasing the government revenues and inevitably led to inflation. But in the 1370s (1990s), with the increase in government revenues, Iran's external debt began to decrease but again with the imposing of cruel sanctions, one can see a decrease in oil revenues and an increase in sovereign external debt. For years, domestic sovereign debts have been considered an important part of sovereign debts but unlike external sovereign debts, domestic sovereign debts have not received enough attention so we encourage further investigations on domestic sovereign debts issues.

In this paper, independent variables were confined to GDP growth, oil revenues, and annual inflation but to gain more insights into governing mechanisms, future researchers can include other relevant macroeconomic variables.

Funding: This research received no external funding. 


\section{References}

Aguiar-Conraria, L., \& Soares, M. J. (2011). Oil and the macroeconomy: using wavelets to analyze old issues. Empirical Economics, 40(3), 645-655.

Aguiar-Conraria, L., Azevedo, N., \& Soares, M. J. (2008). Using wavelets to decompose the time-frequency effects of monetary policy. Physica A: Statistical mechanics and its Applications, 387(12), 2863-2878.

Andersson, F. N., \& Karpestam, P. (2014). Short and long term growth effects of financial crises. In Wavelet Applications in Economics and Finance (pp. 227-248). Springer, Cham.

Arthur, W. B. (1999). Complexity and the economy. Science, 284(5411), 107109.

Awan, R. U., Anjum, A., \& Rahim, S. (2015). An econometric analysis of determinants of external debt in Pakistan. Journal of Economics, Management and Trade, 382-391.

Bahrami, M., Chinichian, N., Hosseiny, A., Jafari, G., \& Ausloos, M. (2020). Optimization of the post-crisis recovery plans in scale-free networks. Physica A: Statistical Mechanics and its Applications, 540, 123203.

Barro, R. J. (1979). On the determination of the public debt. Journal of Political Economy, 87(5, Part 1), 940-971.

Barro, R. J. (1987). Government spending, interest rates, prices, and budget deficits in the United Kingdom, 1701-1918. Journal of monetary economics, 20(2), 221-247.

Bittencourt, M. (2015). Determinants of government and external debt: Evidence from the young democracies of South America. Emerging Markets Finance and Trade, 51(3), 463-472.

Bohn, H. (1990). Tax smoothing with financial instruments. The American Economic Review, 1217-1230.

Bohn, H. (2008). The sustainability of fiscal policy in the United States. Sustainability of public debt, 15- 49.

Casalin, F., Dia, E., \& Hallett, A. H. (2020). Public debt dynamics with tax revenue constraints. Economic Modelling, 90, 501-515.

Cascio, I. L. (2015). A wavelet analysis of US fiscal sustainability. Economic Modelling, 51, 33-37.

Emami, K., \& Adibpour, M. (2010). The asymmetric effects of oil shocks on output in Iran.

Esfahani, H. S., Mohaddes, K., \& Pesaran, M. H. (2014). An empirical growth 
model for major oil exporters. Journal of Applied Econometrics, 29(1), 1-21.

Gallegati, M., \& Semmler, W. (Eds.). (2014). Wavelet applications in economics and finance. Springer International Publishing.

Gallegati, M., Gallegati, M., Ramsey, J. B., \& Semmler, W. (2017). Long waves in prices: new evidence from wavelet analysis. Cliometrica, 11(1), 127-151.

Grinsted, A., Moore, J. C., \& Jevrejeva, S. (2004). Application of the cross wavelet transform and wavelet coherence to geophysical time series.

Hammoudeh, S. (1988). The oil market and its impact on the economic development of the oil-exporting countries. The Journal of Energy and Development, 297-324.

Helbing, D., \& Kirman, A. (2013). Rethinking economics using complexity theory. Real-world economics review, issue, (64).

Hilscher, J., \& Nosbusch, Y. (2010). Determinants of sovereign risk: Macroeconomic fundamentals and the pricing of sovereign debt. Review of Finance, 14(2), 235-262.

Hosseiny, A., Absalan, M., Sherafati, M., \& Gallegati, M. (2019). Hysteresis of economic networks in an XY model. Physica A: Statistical Mechanics and its Applications, 513, 644-652.

Hosseiny, A., Bahrami, M., Palestrini, A., \& Gallegati, M. (2016). Metastable features of economic networks and responses to exogenous shocks. PloS one, 11(10), e0160363.

Lai, Z. K., Namaki, A., Hosseiny, A., Jafari, G. R., \& Ausloos, M. (2020). Coupled criticality analysis of inflation and unemployment. arXiv preprint arXiv:2003.12655.

Namaki, A., Raei, R., \& Jafari, G. R. (2011). Comparing Tehran stock exchange as an emerging market with a mature market by random matrix approach. International Journal of Modern Physics C 22 (04), 371-383

Namaki, A., Raei, R., Asadi, N., \& Hajihasani, A. (2019). Analysis of Iran Banking Sector by Multi-Layer Approach. Iranian Journal of Finance, 3(1), 73-89.

Pearce, D. (1994). Complexity theory and economics. Agenda: A Journal of Policy Analysis and Reform, 101-106.

Raei, R., Namaki, A., \& Vahabi, H. (2019). Analysis of Collective Behavior of Iran Banking Sector by Random Matrix Theory. Iranian Journal of Finance, 3(4), 6075.

Raei, R., Namaki, A., Vahabi, H. (2019). Analysis of Collective Behavior of Iran Banking Sector by Random Matrix Theory. Iranian Journal of Finance, 3(4), 60-75. 
Reinhart, C. M., \& Rogoff, K. S. (2010). Growth in a Time of Debt. American economic review, 100(2), 573-78.

Reinhart, C. M., \& Rogoff, K. S. (2011). From financial crash to the debt crisis. American Economic Review, 101(5), 1676-1706.

Schweitzer, F., Fagiolo, G., Sornette, D., Vega-Redondo, F., Vespignani, A., \& White, D. R. (2009). Economic networks: The new challenges. Science, 325(5939), 422-425.

Shirazi, A. H., Saberi, A. A., Hosseiny, A., Amirzadeh, E., \& Simin, P. T. (2017). Non-criticality of interaction network over the system's crises: A percolation analysis. Scientific reports, 7(1), 1-8.

Tehrani, R., Namaki, A., Hedayatifar, L. (2012). The Cross-correlation Structure of Tehran Stock Exchange Indexes by Multifractal Detrended Fluctuation Analysis. Financial Research Journal, 14(1), 55-68.

Varela, L. M., Rotundo, G., Ausloos, M., \& Carrete, J. (2015). Complex network analysis in socioeconomic models. In Complexity and Geographical Economics (pp. 209-245). Springer, Cham.

Yang, L., Cai, X. J., Zhang, H., \& Hamori, S. (2016). The interdependence of foreign exchange markets: A wavelet coherence analysis. Economic Modelling, 55, 614.

Bibliographic information of this paper for citing:

Namaki, Ali; Nazari, Mohsen \& Gaeeini, Hossein (2020). Analysis of Sovereign External Debt Variations by Cross Wavelet Transform. Iranian Journal of Finance, 4(4), 126-139.

Copyright $@$ C 2020, Ali Namaki, Mohsen Nazari and Hossein Gaeeini 